\title{
The influence of dietary supplementation of arachidonic acid on prostaglandin production and oxidative stress in the Pacific oyster Crassostrea gigas
}

\author{
Catherine Seguineau ${ }^{\mathbf{a}}$, Ilie S. Racotta ${ }^{\mathbf{b}, \mathbf{c}}$, Elena Palacios ${ }^{\mathbf{c}, \mathbf{d}}$, Maryse Delaporte ${ }^{\mathbf{b}}$, Jeanne Moal ${ }^{\mathbf{b}}$ and \\ Philippe Soudant ${ }^{\mathrm{d}, *}$
}

\footnotetext{
a Université de Bretagne Occidentale, Brest, France et UMR 100 Physiologie et Ecophysiologie des Mollusques Marins, Centre IFREMER de Brest, BP70, 29280 Plouzané, France

b UMR 100 Physiologie et Ecophysiologie des Mollusques Marins, Centre IFREMER de Brest, BP70, 29280 Plouzané, France

${ }^{\mathrm{c}}$ Programa de Acuicultura, Centro de Investigaciones Biológicas del Noroeste, Apdo. Postal 128, La Paz B.C.S. 23090, Mexico

d Laboratoire des Sciences de l'Environnement Marin, UMR 6539, Institut Universitaire Européen de la Mer, Université de Bretagne Occidentale, Technopôle Brest-Iroise, 29280 Plouzané, France
}

*: Corresponding author : Philippe Soudant, Tel.: + 33298498623 ; fax: + 332984986 45. ; email address : Philippe.Soudant@univ-brest.fr

\begin{abstract}
:
In a previous study, dietary supplementation with arachidonic acid (ARA) to oysters Crassostrea gigas increased haemocyte numbers, phagocytosis, and production of reactive oxygen species level (ROS) by haemocytes (Delaporte et al., 2006). To assess if the observed stimulation of these cellular responses resulted from changes of ARA-related prostaglandin (PG) production, we analysed prostaglandin E2 metabolite (PGEM) content on the same oysters fed three levels of ARA. Dietary supply of polyunsaturated fatty acids (PUFA) could also induce an oxidative stress that could similarly increase cellular responses; therefore, two indicators of oxidative stress were analysed: peroxidation level and antioxidant defence status. Together the observed positive correlation between ARA and PGEM levels and the absence of lipid peroxidation and antioxidant activity changes supports the hypothesis of an immune stimulation via PG synthesis. Although ARA proportion in oyster tissues increased by up to 7 -fold in response to ARA dietary supplementation, peroxidation index did not change because of a compensatory decrease in $n-3$ fatty acid proportion, mainly $22: 6 n-3$. To further confirm the involvement of PG in the changes of haemocyte count, phagocytosis and ROS production upon ARA supplementation, it would be interesting to test cyclooxygenase and lipooxygenase inhibitors in similar experiments.
\end{abstract}

Keywords : Prostaglandins; n-6 unsaturated fatty acids; Lipid peroxidation; Antioxidants; ROS production 


\section{Introduction}

Altering the composition of phospholipids in immune cells by changing the fatty acids (FA) supplied in the diet can modulate cell immune function and immune response through membrane alterations (raft, order, trafficking), signal transduction pathways, and lipid mediators (e.g. eicosanoids) (Calder, 2008). Eicosanoids are important lipid mediators in inflammation and healing in vertebrates. Eicosanoids include prostaglandins (PG), leukotrienes (LT), thromboxanes (TX), and lipoxins; they are derived from FA, principally ARA, which is released from membrane phospholipids (Pompéia et al., 2000). In mammals, prostaglandin PGE2 and leukotriene LTB4 are two potent immunomodulatory agents produced from ARA by the enzymes cycloxygenase (COX) and 5-lipoxygenase (LOX), respectively (Kelley et al., 2005). In insects, eicosanoids are also important mediators of cellular immune reactions such as phagocytosis, microaggregation, cell spreading, and nodulation reactions (Stanley and Miller, 2006; Merchant et al., 2008). Canesi et al. (2002) demonstrated that eicosanoids are involved in bacterial killing by mussel (Mytilus edulis) hemocytes by using specific inhibitors of COX and LOX.

The relationship between eicosanoids' synthesis and antibacterial response of hemocytes has been demonstrated in bivalve molluscs (Canesi et al., 2002). More recently, the ARA incorporation from diet in phospholipids, as well as their relation to an increase in immune responses: hemocyte number, phagocytic activity, reactive oxygen species (ROS) generation by hemocytes, desensibilization to pathogens (Delaporte et al., 2006) and prostaglandin E2 synthesis (Hurtado et al., 2009) has also been shown. Nevertheless, effects of FA on immune cell activity can also be independent of the changes in the secretion of eicosanoids (Kelley and Ruldoph, 2000). ARA can directly modulate phagocytosis, cytokine production, surface molecule expression, leukocyte migration, and antigen pre 69 sentation through stimulation of superoxide anion generation (Pompéia et al., 2000). Cellular enrichment with PUFA such as ARA has also been demonstrated to elicit in vitro an increase of ROS production and lipid peroxidation (Mazière et al., 1999). The susceptibility of membranes to oxidative damage depends on the degree of polyunsaturation level of FA, measured as peroxidation index (Hulbert et al., 2007). ARA can easily be peroxidized, generating free radicals such as the superoxide anion. Lipid peroxidation is a self propagating process and produces a broad range of reactive intermediates often measured as malondialdehyde (MDA), which has a longer half life than free radicals (Janero, 1990). However, ROS production and lipid peroxidation, generally referred to as "oxidative stress", may also be linked to prostaglandin synthesis from ARA, as it has been demonstrated in rat pheochromocytoma PC12 cells (Jiang et al., 2004) and human neuroblastoma cells (Kondo et al., 2001). All of the above studies suggest that ARA-derived prostaglandins may play an important role in regulation of immune responses including those in bivalve molluscs, such as increased hemocyte count, phagocytosis and ROS production previously reported (Delaporte et al., 2006).

From this perspective, antioxidant status of an organism is of critical significance in determining the effect of PUFA on immune and inflammatory responses (Kelley, 2001). To protect themselves against free radicals and ROS, bivalves like other organisms, possess an array of free radical scavenging antioxidant molecules and antioxidant enzymes like superoxide dismutase (SOD), catalase, and glutathione peroxidase (Manduzio et al., 2004; Monari et al., 2005; Box et al 2007; Cipak et al., 2008), which can be expected to increase upon oxidative stress and/or lipid peroxidation, potentially induced by ARA incorporation into tissues. In this work, we analyzed PGE2 metabolite (PGEM) levels, antioxidant capacity, enzymatic activities of catalase and SOD and lipid peroxidation in relation to the ARA supplementation of diet in oysters. It aimed to test the hypothesis that changes of hemocyte counts, phagocytosis

and ROS production upon ARA supplementation, as reported by Delaporte et al. (2006) involved prostaglandins.

\section{Materials and methods}

\subsection{Oyster dietary treatments, sample collection and processing}

One year old oyster Crassostrea gigas were collected from the field (Aber-Benoît, Finistère, Brittany) and fed Isochrysis galbana clone Tahitian (T.iso), during an acclimation period of 10 days. ARA was supplemented twice a day directly into the water. The daily algal ration was established at $4 \%$ algal dry weight per oyster dry weight and supplied continuously into the 
tanks holding the oysters. Water in the tanks was renewed twice a day with $1 \mu \mathrm{m}$ filtered seawater using a flow through system. As described by Delaporte et al. (2006), three levels of supplementation with ARA solution (Sigma, A-9376) were tested during 4 weeks: a control with $0 \mu \mathrm{g}$ ARA, and two concentrations of ARA: 0.25 and $0.41 \mu \mathrm{g} / \mathrm{mL}$ of sea water. Oysters were sampled after $15(\mathrm{n}=15)$ and 30 days $(\mathrm{n}=15)$ of supplementation with ARA. At each sampling time, three pools of 5 animals were constituted. Whole tissue of oysters was frozen and stored in liquid nitrogen at $-196{ }^{\circ} \mathrm{C}$. The samples were ground with a Dangoumeau homogeniser, and the powder was used for all the parameters analysed here.

\subsection{Fatty acid analysis}

Ground tissue $(300 \mathrm{mg}$ ) was transferred to a tube containing $6 \mathrm{~mL}$ of chloroform-methanol mixture $(2: 1, \mathrm{v}: \mathrm{v})$. After centrifugation, the lipid extract was transferred to a clean tube, sealed under nitrogen, and stored at $-20^{\circ} \mathrm{C}$. Neutral lipids (lipid reserves) and polar lipids (membrane lipids) were separated on a Silica gel micro-column as described by Marty et al. (1992), and fatty acids in each fraction were analysed as described by Delaporte et al. (2006). Fatty acid composition was expressed as percentage of total FA in each lipid fraction and as $\mu \mathrm{g}$ of FA per mg of oyster wet mass. The unsaturation index (PUI) and peroxidation index was calculated as described by Hulbert (2007):

Unsaturation index $(\mathrm{PUI})=1 \times(\%$ monoenoics $)+2 \times(\%$ dienoics $)+3 \times(\%$ trienoics $)+4 \times(\%$ tetraenoics $)+5 \times(\%$ pentaenoics $)+6 \times(\%$ hexaenoics $)$

Peroxidation index $=0.025 \times(\%$ monoenoics $)+1 \times(\%$ dienoics $)+2 \times(\%$ trienoics $)+4 \times(\%$ tetraenoics $)+6 \times(\%$ pentaenoics $)+8 \times(\%$ hexaenoics $)$

\subsection{Prostaglandin analysis}

Prostaglandin $\mathrm{E}_{2}$ metabolite (PGEM) was assayed by the PG screening EIA Kit (Cayman Chemical No. 514531, Ann Arbor, MI, USA). As indicated in the Cayman Kit, $\mathrm{PGE}_{2}$ is rapidly converted in vivo to PGEM and so measurement of this metabolite is more reliable for estimation of actual $\mathrm{PGE}_{2}$ production in biological samples. According to the recommendations of the manufacturer, a purification step was performed on C-18 SPE cartridges (Waters, Milford, MA, USA). An aliquot of tissue $(20 \mathrm{mg})$ was mixed in $500 \mu \mathrm{L}$ water and incubated at 4 ${ }^{\circ} \mathrm{C}$ for $5 \mathrm{~min}$ with $2 \mathrm{~mL}$ ethanol, and then centrifuged at $1000 \mathrm{~g}$ for $10 \mathrm{~min}$ to precipitate proteins. The assay was performed on supernatant according to the protocol described in the kit. Samples and standards were transferred to microplates coated with mouse monoclonal antibodies against rabbit antibodies. Specific rabbit antibody against PGEM and tracer consisting of acetylcholinesterase (AChE) coupled to PGEM were added, and plates were 
139 incubated for $18 \mathrm{~h}$. After several washings, Ellman's reagent (substrate and chromogen) was

140 added to measure AChE activity which is determined spectrophotometrically at $415 \mathrm{~nm}$ with a 141 microplate reader (Bio-Tek Synergy HT, Bio-Tek Instrument, USA). Absorbance is proportional 142 to the amount of PGEM from the tracer bound to the well which is inversely proportional to free 143 PGEM from sample. Results are expressed in pg of PGEM per mg of tissue wet mass. Due to 144 the high levels of ARA in tissues in this experiment compared to measured levels of PG, the 145 cross reactivity was tested. The tests showed that $71 \%$ of free ARA and $64 \%$ of free EPA are 146 lost during the purification step, and cross-reactivity of ARA in the tissue at the concentration 147 used here with the EIA Kit was around 0.002\% (Reza, 2009), in accordance with kit 148 specifications of less than $0.01 \%$.

\subsection{Assay of lipid peroxidation}

151 Lipid peroxides derived from polyunsaturated fatty acids are unstable and decompose to other complex compounds of which malondialdehyde (MDA) is the most abundant. The MDA was measured by a spectrophotometric assay using a commercial kit (MDA-586 BIOXYTECH method, Oxis Research, Portland, OR, USA). The method is based on the reaction of a chromogenic reagent, $\mathrm{N}$ methyl-2-phenylindole with MDA at $45^{\circ} \mathrm{C}$. Oyster powder $(100 \mathrm{mg})$

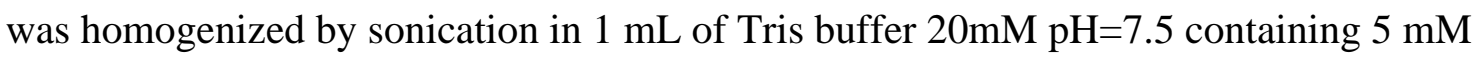
butylated hydrotoluene (BHT) to avoid intra-assay oxidation. The homogenate was centrifuged at $15000 \mathrm{~g}\left(15 \mathrm{~min}, 4^{\circ} \mathrm{C}\right)$ and the supernatant was added to a mixture of probucol N-methyl-2phenylindole, hydrochloric acid as indicated in the kit. The reaction was performed at $45^{\circ} \mathrm{C}$ for $60 \mathrm{~min}$. After centrifugation at $10000 \mathrm{~g}$ (10 $\mathrm{min})$, the clear supernatant was transferred into a microtitration plate and the absorbance was measured at $586 \mathrm{~nm}$. A standard curve was established with a solution of tetramethoxypropane (TMP) hydrolysed during the acid incubation step generating MDA. The result is expressed in $\mu$ mol MDA per $g$ of wet mass.

\subsection{Total antioxidant radical scavenging capacity (TARSC)}

166 TARSC was analyzed by the method described by Fukumoto and Mazza (2000), which uses 2,2 167 diphenyl-1-picrylhydrazyl (DPPH) as a free radical. This method is based on the analysis of 168 absorbance decrease of DPPH in presence of any antioxidant compound. Antioxidant 169 compounds were extracted from $150 \mathrm{mg}$ oyster powder with $1 \mathrm{~mL}$ mixture of methanol and 170 water (50/50). After sonication, the homogenate was centrifuged at $3500 \mathrm{~g}\left(15 \mathrm{~min}, 4{ }^{\circ} \mathrm{C}\right)$ and the supernatant was added to $150 \mu \mathrm{M}$ DPPH solution in a microtitration plate. The plate was covered and incubated in the dark at room temperature and the absorbance was measured at 520 $\mathrm{nm}$ after 30 and $60 \mathrm{~min}$. A mixture of methanol:water was used as blank. As a positive control, 
174 butylated hydroxyanisole (BHA) standard was used. The total antioxidant radical scavenging

175 activity (TARSC) was expressed as DPPH inhibition percentage: (Blank OD - Sample

176 OD)/Blank OD×100 during a 30 min incubation (Moncheva et al., 2004).

\section{$178 \quad 2.6$ Antioxidant enzymes}

179 For enzymatic assays, an aliquot of ground powder was homogenized by sonication in 180 phosphate buffer $0.01 \mathrm{M}, \mathrm{pH}=7.4$ with $0.1 \%$ triton and $1 \mathrm{mM}$ EDTA and centrifuged at $15000 \mathrm{~g}$ 181 (15 $\left.\mathrm{min}, 4^{\circ} \mathrm{C}\right)$. The supernatant was used for enzymatic assays, catalase and superoxide 182 dismutase (SOD).

\section{Catalase activity}

185 Catalase (EC 1.11.16) activity was measured with a commercial kit (Amplex Red Catalase assay 186 kit, Molecular probes Invitrogen, Oregon USA) in which catalase first reacts (30min) with $\mathrm{H}_{2} \mathrm{O}_{2}$ to produce water and oxygen. Then, the Amplex Red reagent provided in the kit reacts with an unreacted $\mathrm{H}_{2} \mathrm{O}_{2}$ in the presence of horseradish peroxidase to produce a highly fluorescent oxidation product, resorufin, with a maximum absorption at $540 \mathrm{~nm}$. A control without catalase was used. Results were expressed in $\mathrm{U} / \mathrm{mg}$ wet mass from a standard curve of catalase activity between 0 to $2.5 \mathrm{U} / \mathrm{mL}$.

Superoxide dismutase (SOD) activity

194 The total SOD (EC 1.15.1.1) activity was determined with the xanthine oxidase-cytochrome C method according to Marie et al. (2006) with some modifications. The assay is based on competition between SOD and cytochrome $\mathrm{C}$ for superoxide anions generated by the reaction of hypoxanthine with xanthine oxidase. The reduction rate of cytochrome $\mathrm{C}$ was measured at 550 $\mathrm{nm}$ in phosphate buffer 50mM with $0.18 \mathrm{mM}$ EDTA, $100 \mathrm{mM}$ hypoxanthine, $30 \mu \mathrm{M}$ cytochrome

$199 \mathrm{C}$ and $20 \mu \mathrm{l}$ of diluted sample. The reaction was initiated by addition of $20 \mu \mathrm{l}$ of xanthine oxidase

$200(0.05 \mathrm{U} / \mathrm{mL})$. The results were expressed as U SOD per mg wet mass.

\subsection{Statistical analysis}

203 Measured parameters were checked for normality and homogeneity (Sokal \& Rohlf, 1995).

204 Percentages were transformed to arcsin (square root) before statistical analysis but are shown as untransformed data. One-way analyses of variance (ANOVA) were applied for all variables to detect significant effects of different levels of ARA supplementation during 15 and 30 days. An additional one way ANOVA was also used to analyse the differences as a result of time of conditioning (15 and 30 days $v$ s. initial values) for the treatment with T.iso + ARA $0 \mu \mathrm{g} / \mathrm{mL}$. 
209 Differences between means for each group were determined by a post-hoc Tukey test. Pearson's

210 correlation analysis was done to define the association between prostaglandin and ARA

211 concentrations in whole oyster. Analyses were performed using STATISTICA $^{\mathrm{TM}}$ version 5.5

212 and differences were reported as significant if $P \leq 0.05$. Data are reported as mean \pm standard

213 error (SE).

214

215

\section{Results}

216

\subsection{Fatty acid composition in phospholipids and lipid reserves}

The fatty acids composition of oysters after 30 days treatment with three ARA concentrations is shown in Table 1. The proportion of 20:4n-6 in phospholipids and lipid reserves increased with increasing levels of this fatty acid in oyster diet. The proportion of 20:4n-6 was higher in phospholipids (membrane lipids) than neutral lipids (lipid reserves), reaching final concentration of $9.2 \%$ and $7.5 \%$, respectively, for the highest level of ARA in the diet. The increase of 20:4n6 resulted in significant decreases $(P<0.05)$ in other PUFA such as 18:3n-3 and 22:6n-3. These relative changes in individual fatty acids following ARA supplementation led to a significant increase $(P<0.05)$ of total $n-6$ fatty acids and a decrease of total n-3 fatty acids, as well as the n3/n-6 and 20:5n-3/20:4n-6 ratio. A slight, but significant increase $(P<0.05)$ of total PUFA and PUI in lipid reserves was observed for the highest ARA $(0.41 \mu \mathrm{g} / \mathrm{mL})$ treatment, whereas in phospholipids this effect was observed for both levels of ARA supplementation. However, no differences were observed in lipid peroxidation index. When expressed as absolute concentration ( $\mu \mathrm{g} / \mathrm{mg}$ wet mass), 20:4n-6 increased 4 and 7 fold in lipid reserves and 2.8 and 4.4 fold in phospholipids for the 0.25 and $0.41 \mu \mathrm{g} / \mathrm{mL}$ treatments, respectively (Fig. 1).

\subsection{Prostaglandin levels and correlation with 20:4n-6}

234 After 15 days, levels of prostaglandin $\mathrm{E}_{2}$ metabolite (PGEM) increased, though not significantly, with increasing ARA levels in the diet (Fig. 2). Levels of PGEM continued to increase after 30 days in both groups supplemented with ARA, with significant differences $(P<0.05)$ observed between both supplemented groups and the control group. In addition, PGEM levels in control oysters were significantly lower $(P<0.05)$ at both 15 and 30 days, as compared to the beginning of the experiment. A significant correlation $\left(\mathrm{R}^{2}=0.67, P<0.01\right)$ between PGEM and ARA concentrations in total lipids (combining lipid reserves and phospholipids) in whole oysters was observed after 30 days (Fig. 3).

\subsection{Lipid peroxidation and antioxidant capacity.}


244 No difference in lipid peroxidation, expressed as MDA concentration, was observed following

245 ARA supplementation at different doses and times (Table 2). Similar results were obtained with 246 the more common method measuring TBARS (results not shown). The total antioxidant radical 247 scavenging capacity (TARSC), inferred from the DPPH inhibition percentage, was not 248 influenced by the time of conditioning, but there was a significant increase of the TARSC for 249 the oysters supplemented with the highest dose of ARA $(0.41 \mu \mathrm{g} / \mathrm{mL})$ at day 15 after 250 conditioning, although this effect was no longer observed after 30 days.

251 The antioxidant capacity was also inferred from the activity of the antioxidant enzymes, SOD 252 and catalase (Table 2). The catalase activity was not influenced by ARA supplementation, as no 253 effect of ARA dose and time of conditioning was observed (Table 2). The SOD activity was not 254 influenced by ARA concentration; however, a significant increase with time of conditioning was 255 observed for the control group (Table 2).

256

257

\section{Discussion}

258

259

Supplementing ARA directly into the water as free FA has been previously reported to increase 260 concentration of this FA in lipid reserves and phospholipids of oyster spat (Seguineau et al., 2005). Supplementation with esterified forms of ARA seems to influence only the ARA accumulation in lipid reserves of oysters (Hurtado et al., 2009). Supply of dissolved ARA directly into the water where oyster are grown appeared thus to be more efficient for ARA incorporation in polar lipids (Delaporte et al., 2006). This could reflect a difference of absolute amount of ARA supplied/ingested, or a better digestibility and absorption of free ARA compared to esterified ARA (Kinsella, 1991). Additionally, differences in oyster species, frequency of ARA feeding and microalgae diet used in the above studies could also explain such differences in ARA incorporation. ARA accumulation seems to be tissue specific as a much stronger incorporation of ARA in gill phospholipids (19.7\%) (Delaporte et al., 2006) than in the whole animal phospholipids (9.3\%, present study, same experiment as Delaporte et al. (2006) was observed. Gills might be incorporating the dissolved form of ARA more readily, as was proposed by Delaporte et al. (2006). However, a higher proportion of ARA in gill phospholipids (6.2\% of total fatty acids, Delaporte et al., 2006) compared to whole organism $(2.3 \%$ of total fatty acids, present study) was observed even in control oysters not fed dissolved ARA.

275 Therefore, the incorporation of ARA into membrane phospholipids of gills could be associated with a tissue-specific function. In other aquatic organisms, ARA is selectively incorporated (reaching up to $20-30 \%$ of total fatty acids) in gill phospholipids of fish (German and $\mathrm{Hu}, 1990$; 
278 Harel et al., 2000; Fountoulaki et al., 2003) and crabs (Lucu et al., 2008), where it modulates

$279 \mathrm{Na} / \mathrm{K}-\mathrm{ATPase}$ activity during osmoregulation (Van Anholt et al., 2004).

280 Oyster fed ARA decreased their levels of n-3 PUFA in tissues. The reduction of n-3 was mainly

281 attributable to docosahexaenoic acid (DHA) (22:6n-3), while the proportion of eicosapentaenoic

282 acid (EPA) (20:5n-3) remained relatively constant. In contrast, EPA was the main n-3 FA to

283 decrease when given diets rich in n-6 to fish (Bell et al., 1992; 1993). The importance of EPA

284 over other n-3 fatty acids in oyster has been previously proposed for maturation (Soudant et al.,

285 1999) and immune response (Delaporte et al., 2007). This relative compensation of total PUFA

286 by a decrease in DHA rather than that of EPA suggest a different role for EPA in molluscs as

287 compared to vertebrates.

288 In our previous study (Delaporte et al., 2006), supplementation with ARA to adult oysters at

2890.25 and $0.41 \mu \mathrm{g} / \mathrm{mL}$ directly in seawater tended to increase total hemocyte counts after 15 and

29030 days of dietary conditioning. Phagocytosis was significantly impacted by ARA

291 supplementation after 15 days of feeding while the strongest impact of ARA supplementation

292 (both doses as compared to control) was observed for ROS production (a two-fold increase)

293 after 4 weeks of ARA supplementation. Furthermore, hemocytes of oysters fed ARA were less

294 sensitive to extracellular products of a pathogenic Vibrio aestuarianus. Relationships between

295 ARA supplementation and cellular immune responses in C. gigas could be explained by

296 different mechanisms: 1) a specific immune response mediated by PG or other eicosanoids such

297 as leukotriene $\mathrm{LTB}_{4}$ and/or 2) a direct action of ARA through changes of membrane

298 composition and/or 3) lipid peroxidation of ARA generating free radicals and modifying thus,

299 immune cell functioning.

300 We found a positive correlation between ARA levels in C. gigas tissues and PGEM

301 concentration after feeding ARA for 30 days. Accordingly, in C. corteziensis ARA-rich

302 emulsions supplemented in the diet increased PGEM levels in oyster tissues in a dose dependent

303 manner (Hurtado et al., 2009). Also, the effects of membrane fatty acid composition, diets rich

304 in 18:2n-6 and ARA or the ARA content of immune cell phospholipids on the production and

305 type of PG and other eicosanoids has been reported in fish and mammals (Bell et al., 1992,

306 1993; Tocher et al., 1997; Peterson et al.,

307 1998; Lund et al., 2008; Villalta et al., 2008). Therefore, it is likely that ARA supply to oysters

308 could promote the increase in other eicosanoids such as leukotrienes ( $\left.\mathrm{LTB}_{4}\right)$ in addition to PG.

309 In vertebrates, it has been shown that $\mathrm{LTB}_{4}$ increase together with $\mathrm{PGE}_{2}$ as a direct result of

310 ARA proportion in immune cell membrane phospholipids, and both are modulated in parallel by

311 ARA dietary supply (Kelley, 2001; Calder, 2008).

312 The proinflammatory influence of ARA in humans is well known; it can significantly increase 
313 the number of circulating neutrophils, the in vitro production of $\mathrm{PGE}_{2}$ and $\mathrm{LTB}_{4}$ by the

314 stimulated peripheral blood mononuclear cells, and the secondary response to influenza vaccine

315 (Kelley, 2001). $\mathrm{PGE}_{2}$ and $\mathrm{PGI}_{2}$ are the predominant pro-inflammatory prostanoids, although

316 they can also exert immuno-suppressive effects and can be involved in the resolution of the

317 inflammation (Stables and Gilroy, 2011). $\mathrm{LTB}_{4}$ is a powerful pro-inflammatory agent that

318 stimulates phagocytosis, chemotaxis and aggregation in neutrophils as well as the release of

319 lysozyme and the generation of oxygen radicals (Toda et al., 2002) and is important in the host

320 response against infection by enhancing microbicidal activities (Stables and Gilroy, 2011).

321 A link between PG and immune responses in molluscs was given by Canesi et al. (2002), who

322 provided indirect information through inhibition of phospholipase A2 and COX on eicosanoid

323 involvement in bacterial killing by mussel (M. edulis) hemocytes. In contrast, no relationship

324 was established between eicosanoids produced through COX and LOX pathways in hemocytes

325 and the immune capacities of the starfish Asterias rubens (Pope et al., 2007). In addition to

326 different responses among species, effects of eicosanoids may vary according to their

327 concentration; small doses of $\mathrm{PGE}_{2}$ and $\mathrm{LTB}_{4}$ stimulate some of the immune cells, whereas

328 higher concentrations inhibit the same cells (Kelley, 2001). This may explain the differences of

329 hemocyte time responses according to parameters; ARA supplementation resulted in a

330 temporary increase in phagocytosis after 2 weeks, but no longer observed after 4 weeks.

331 However, ROS production only increased after 4 weeks of ARA supplementation.

332 A number of studies using COX and LOX inhibitors in vertebrates indicate that the effects of

333 FA on immune cell activity can be independent of the changes in the secretion of eicosanoids

334 (Kelley and Rudolph, 2000; Pompéia et al., 2000). Changes of the FA composition of immune

335 cells can directly affect phagocytosis, ROS production, cytokine production, leukocyte

336 migration, T-cell signalling and antigen presentation capability (Pompéia et al., 2000; Calder,

337 2008). A dose-dependent effect of ARA on superoxide anion production through NADPH-

338 oxidase system but independent of eicosanoid production was observed in human and rat

339 leucocytes (Pompéia et al., 2003). Such direct effects of ARA on oyster hemocyte functions

340 deserve to be explored by using COX and LOX inhibitors on hemocytes collected from oysters

341 fed different levels of ARA.

342 As mentioned before, the effect of ARA supplementation on hemocyte activities was observed

343 on ROS production after 4 weeks; it can be hypothesized that lipid peroxidation of ARA

344 generated free radicals which in turn leads to superoxide anion production. Peroxidation and

345 autoxidation of PUFA are general mechanisms for ROS production (Peck, 1994b). PUFA in

346 membranes are more prone to lipotoxicity producing structural changes that may lead to cell

347 damage (Gonzalez-Flecha et al., 1992), decreased membrane fluidity, oxidation of thiol groups 
of enzymes in the membranes, and liberation of breakdown products which produce damage elsewhere (Peck, 1994a). By supplementing high quantities of ARA in the oyster's diet, we expected to increase the quantity of double bonds, and thus the unsaturation (PUI) and peroxidation indices (Table 1). PUI of reserve and membrane lipids increased significantly upon ARA supplementation at $0.4 \mu \mathrm{g} / \mathrm{mL}$ while peroxidation index was not affected. This may indicate a tight regulation of double bonds in both reserve and membrane lipids, possibly to limit exposure to lipid peroxidation when oysters are exposed to PUFA enriched diet. The increase of ARA in both membrane and reserve lipids was mainly compensated by decreases of DHA which has two more double bonds than ARA and of 18:3n-3 which has one less double bond.

Nevertheless, this does not exclude that ARA supplementation may have resulted in lipid peroxidation that should be inferred through the production of by-products such as malondialdehyde (MDA). MDA has been reported to occur at rates 200-times higher than the rates of $\mathrm{PGE}_{2}$ synthesis in vertebrate kidneys; so ARA, together with other PUFA would be much more likely to be peroxidized by oxygen free radicals than to be used for PG synthesis (Gonzalez-Flecha et al., 1992). However, in good agreement with the absence of significant changes in peroxidation index of reserve and membrane lipids, no significant differences in MDA content was found according to ARA supplementation levels.

To further test if ARA supplementation changed the oxidative status of the whole oysters, it was important to assess the antioxidant capacities and activities of oysters exposed to increasing dietary supply of ARA. Box et al. (2007) stated that an adaptation response of enzymes activities and no significant differences in MDA concentration indicated that the antioxidant response was able to avoid lipid peroxidation. Environmental stressors such as dissolved oxygen influence antioxidant enzyme activities (SOD, catalase, and glutathione peroxidase GPX) in Mytilus galloprovincialis (Santovito et al., 2005), clams Chamelea gallina (Monari et al., 2005) and blue mussels Mytilus edulis (Manduzio et al., 2004). Moncheva et al. (2004) demonstrated that the antioxidant capacity of whole tissue of mussels is higher in polluted sites. Moreover, antioxidant status is of critical significance in determining the effects of PUFA on immune and inflammatory responses (Kelley et al., 2001). In the present study, no significant differences in catalase or SOD activities in relation to ARA supplementation were observed, suggesting the general antioxidant enzyme pathway was not activated. Only a temporary but significant increase of antioxidant capacity in terms of percent inhibition of DPPH was found after 15 days of ARA enrichment at $0.41 \mu \mathrm{g} \cdot \mathrm{mL}^{-1}$. Such transitory response remains unexplained. However, from lipid peroxidation status and the overall antioxidant capacity evaluated in the present study, it appears that ARA supplementation unlikely resulted in a substantial and sustained 
oxidative stress.

384

385

386

387

388

389

390

391

392

393

394

395

396

397

398

399

400

401

402

403

404

405

406

407

408

409

410

411

412

413

414

415

416

417

418

419

420

\section{Conclusions}

\section{Acknowledgments}

\section{References} 335-342.

The effect of supplementing ARA in the diet on oyster hemocyte parameters could be mediated through synthesis of PG and involves several cellular immune responses (number of circulating hemocytes, phagocytosis, ROS production, susceptibility to bacterial virulence factors). The lack of lipid peroxidation and activation of antioxidant responses upon increased ARA levels in diet indicate that immune responses could not be attributed to a general increase in oxidative stress. To further establish the involvement of PG in the observed cellular changes (hemocyte count, phagocytosis and ROS production), it would be interesting to test COX and LOX inhibitors in future experiments.

The authors would like to thank A. Volety for his constructive comments. This research was funded by project 49191 (SEP-CONACYT, given to E. Palacios). The authors thank Monica Reza for her help during PGEM analysis. Ilie S. Racotta and Elena Palacios were recipients of CONACYT, CNRS or Ifremer fellowships for sabbatical stay at Brest, France.

Bell, J.G., Dick, J.R., Sargent, J.R., Thompson, K.D., 1992. Effects of increasing dietary linoleic acid on phospholipid fatty acid composition and eicosanoid production in leucocytes and gill cells of Atlantic salmon (Salmo salar). Prostaglandins Leukotr. Essent. Fatty Acids 45, 197-203.

Bell, J.G., Dick, J.R., Mc Vicar, A.H., Sargent, J.R., Thompson, K.D., 1993. Dietary sunflower, linseed and fish oils affect phospholipid fatty acid composition, development of cardiac lesions, phospholipase activity and eicosanoid production in Atlantic salmon (Salmo salar). Prostaglandins Leukot. Essent. Fatty Acids 49, 665-673.

Bell, J.G., Tocher, D.R., Sargent, J.R., 1994. Effect of supplementation with 20:3(n - 6), 20:4(n - 6) and 20:5(n - 3) on the production of prostaglandins $E$ and $F$ of the 1-, 2- and 3-series in turbot (Scophthalmus maximus) brain astroglial cells in primary culture. Biochim. Biophys. Acta 1211,

Box, A., Sureda, A., Galgani, F., Pons, A., Deudero, S., 2007. Assessment of environmental pollution at Balearic Islands applying oxidative stress biomarkers in the mussel Mytilus galloprovincialis. Comp. Biochem. Physiol. C 146, 531-539.

Calder, P., 2006. Polyunsaturated fatty acids and inflammation. Prostaglandins Leukot. Essent. Fatty Acids 75, 197-202.

Calder, P., 2008. The relationship between the fatty acid composition of immune cells and their function. Prostaglandins. Leukot. Essent. Fatty Acids.79, 101-108. 
Canesi, L., Scarpatoa, A., Bettia, M., Ciaccia, C., Pruzzo, C., Galloc, G., 2002. Bacterial killing by Mytilus hemocyte monolayers as a model for investigating the signaling pathways involved in mussel immune defence. Mar. Environ. Res. 54, 547-551.

Cipak, A., Jaganjac, M., Tehlivets, O., Kohlwein, S.D., Zarkovic, N., 2008. Adaptation to oxidative stress induced by polyunsaturated fatty acids in yeast. Biochim. Biophys. Acta 1781, 283-287.

Delaporte, M., Soudant, P., Moal, J., Lambert, C., Quéré, C., Miner, P., Choquet, G., Paillard, C., Samain, J.F, 2003. Effect of a mono-specific algal diet on immune functions in two bivalve species Crassostrea gigas and Ruditapes philippinarum. J. Exp. Biol. 206, 3053-3064.

Delaporte, M., Soudant, P., Moal, J., Giudicelli, E., Lambert, C., Séguineau, C., Samain, J.F, 2006. Impact of 20:4n-6 supplementation on the fatty acid composition and hemocyte parameters of the Pacific Oyster Crassostrea gigas. Lipids 41, 567-576.

Delaporte, M., Chu, F.L., Langdon, C., Moal, J., Lambert, C., Samain, J.F., Soudant, P., 2007. Changes in biochemical and hemocyte parameters of the pacific oysters Crassostrea gigas fed T-Iso supplemented with lipid emulsions rich in eicosapentaenoic acid. J. Exp. Mar. Biol. Ecol. 343, 261-275.

Eligini, S., Arenaz, I., Barbieri, S.S., Faleri , M.L., Crisci, M., Tremoli, E., Colli, S., 2009. Cyclooxygenase-2 mediates hydrogen peroxide-induced wound repair in human endothelial cells. Free. Radic. Biol. Med. 46, 1428-1436.

Fountoulaki, E., Alexis, M.N., Nengas, I., Venou, B., 2003. Effects of dietary arachidonic acid (20:4n-6), on growth, body composition, and tissue fatty acid profile of gilthead bream fingerlings (Sparus aurata L.). Aquaculture 225, 309-323.

Fukumoto, L.R., Mazza, G., 2000. Assessing antioxidant and prooxidant activities of phenolic compounds. J. Agric. Food Chem. 48, 3597-3604.

German, J.B., Hu, M.L., 1990. Oxidant stress inhibits the endogenous lipoxygenase metabolites in rat lungs production of and fish gills. Free. Rad. Biol. Med. 8, 441-448.

Gonzalez-Flecha, B., Evelson, P., Sterin-Speziale, N., Boveris, A., 1993. Hydrogen peroxide metabolism and oxidative stress in cortical, medullary and papillary zones of rat kidney. Biochim. Biophys. Acta 1157, 155-161.

Harel, M., Lund, E., Gavasso, S., Herbert, R., Allen R., 2000. Place modulation of arachidonate and docosahexaenoate in Morone chrysops larval tissues and the effect on growth and survival. Lipids $35,1269-1280$.

Hermes-Lima, M., Zenteno-Savín, T., 2002. Animal response to drastic changes in oxygen availability and physiological oxidative stress. Comp. Biochem. Physiol. C 133, 537-556.

Hulbert, A.J., Pamplona, R., Buffenstein, R., Buttemer, W.A., 2007. Life and death: Metabolic rate, membrane composition, and life span of animals. Physiol. Rev. 87, 1175-1213.

Hurtado, M.A., Reza, M., Ibarra A.M., Wille, M., Sorgeloos, P., Soudant, P., Palacios, E., 2009. Arachidonic acid (20:4n-6) effect on reproduction, immunology, and prostaglandin E2 levels in Crassostrea corteziensis (Hertlein, 1951). Aquaculture 294, 300-305.

Janero, D.R., 1990. Malondialdehyde and thiobarbituric acid-reactivity as diagnostic indices of lipid peroxidation and peroxidative tissue injury. Free Radic. Biol. Med. 9, 515-540.

Jiang, J., Borisenko, G.G., Osipov, A., Martin, I., Chen, R., Shvedova, A.A., Sorokin, A., Tyurina, Y.Y., Potapovich, A., Tyurin,V.A., Graham, S.H., Kagan, V.E., 2004. Arachidonic acid-induced carboncentered radicals and phospholipid peroxidation in cyclo-oxygenase-2-transfected PC12 cells. J. Neurochem. 90, 1036-1049.

Kelley, D.S., Rudolph, I.L., 2000. Effect of individual fatty acid of w-6 and w-3 type on human immune status and role of eicosanoids. Nutrition 16, 143-145. 
Kelley, D.S., 2001. Modulation of human immune and inflammatory responses by dietary fatty acids. Nutrition 17, 669-673.

Kelley, D.S., Hubbard, N.E., Erickson, K.L., 2005. Regulation of human immune and inflammatory responses by dietary fatty acids. Adv. Food. Nutr. Res. 50, 101-138.

Kinsella, J.E., 1991. $\alpha$-linolenic acid: Functions and effects on linolenic acid and metabolism and eicosanoid -mediated reactions. Adv. Food. Nutr. Res. 35, 1-184.

Kondo, M., Oya-Ito, T., Kumagai, T., Osawa, T., Uchida, K., 2001. Cyclopentenone prostaglandins as potential inducers of intracellular oxidative stress. J. Biol. Chem. 276, 12076-12083.

Lucu, C., Pavičić, J., Ivanković, D., Pavičić-Hamer, D., Najdek, M., 2008. Changes in Na+/K+-ATPase activity, unsaturated fatty acids and metallothioneins in gills of the shore crab Carcinus aestuarii after dilute seawater acclimation. Comp. Biochem. Physiol. A 149, 362-372.

Lund, I., Steenfeldt, S.V., Banta, G., Hansen, B.W., 2008. The influence of dietary concentrations of arachidonic acid and eicosapentaenoic acid at various stages of larval ontogeny on eye migration, pigmentation and prostaglandin content of common sole larvae (Solea solea L.). Aquaculture. 276, 143-153.

Manduzio, H., Monsinjon, T., Galap, C., Leboulenger, F., Rocher, B., 2004. Seasonal variations in antioxidant defences in blue mussels Mytilus edulis collected from a polluted area: major contributions in gills of an inducible isoform of $\mathrm{Cu} / \mathrm{Zn}$-superoxide dismutase and of glutathione $\mathrm{S}$ transferase. Aquat. Toxicol. 70, 83-93.

Marie, B., Genard, B., Rees, J.F., Zal, F., 2006. Effect of ambient oxygen concentration on activities of enzymatic antioxidant defences and aerobic metabolism in the hydrothermal vent worm, Paralvinella grasslei. Mar. Biol. 150, 273-284.

Marty, Y., Delaunay, F., Moal, J., Samain, J.F., 1992. Change in the fatty acid composition of Pecten maximus (L.). J. Exp. Mar. Biol. 163, 221-234.

Mazière, C., Conte, M.A, Degonville, J., Ali D., Mazière, J.C., 1999. Cellular enrichment with polyunsaturated fatty acids induces an oxidative stress and activates the transcription factors AP1 and NFkB star. Biochem. Biophys. Res. Comm. 265, 116-122.

Merchant, D., Ertl, R.L., Rennard, S.I., Stanley, D.W., Miller, J.S., 2008. Eicosanoids mediate insect hemocyte migration. J. Insect Physiol. 54, 215-221.

Monari, M., Matozzo, V., Foschi, J., Marin, M.G., Cattani, O., 2005. Exposure to anoxia of the clam, Chamelea gallina II: Modulation of superoxide dismutase activity and expression in haemocytes. J. Exp. Mar. Biol. Ecol. 325, 175-188.

Moncheva, S., Trakhtenberg, S., Katrich,E., Zemser, M., Goshev,I., Toledo, F., Arancibia-Avila, P., Doncheva,V., Gorinstein, S., 2004. Total antioxidant capacity in the black mussel (Mytilus galloprovincialis) from Black Sea coasts. Estuar. Coast. Shelf. Sci. 59, 475-484.

Peck, M.D., 1994 a. Interaction of lipids with immune function I: Biochemical effects of dietary lipids on plasma membranes. J. Nutr. Biochem. 5, 466-478.

Peck, M.D., 1994 b. Interactions of lipids with immune function II: Experimental and clinical studies of lipids and immunity. J. Nutr. Biochem. 5, 514-521.

Peterson, L.D., Jeffery, N.M., Thies, F., Sanderson, P., Newsholme, A.A, Calder, P.C., 1998. Eicosapentaenoic and docosahexaenoic acids alter rat spleen leukocyte fatty acid composition and prostaglandin E2 production but have different effects on lymphocyte functions and cell-mediated immunity. Lipids 33, 171-180.

Pompéia, C., Lopes, L.R., Miyasaka, C.K., Procópio, J., Sannomiya, P., Curi, R., 2000. Effect of fatty acids on leucocyte function. Braz. J. Med. Biol. Res. 33, 1255-1268.

Pompéia, C., Cury-Boaventura, M.F., Curi, R., 2003. Arachidonic acid triggers an oxidative burst in leukocytes. Bra. J. Med. Biol. Res. 36, 1549-1560. 
Pope, E.C., Taylor, G.W., Rowley, A.F., 2007. Biosynthesis and functions of eicosanoids generated by the coelomocytes of the starfish, Asterias rubens. Comp. Biochem. Physiol. B 147, 657-666.

Reza, M. 2009. Implementación del análisis de prostaglandinas en tejidos de ostión y comparación de prostaglandina E2 después de un estrés por muestreo en ostión de placer (Crassotrea corteziensis) y ostión Japonés (C. gigas) y durante el desove de $C$. gigas. Master Thesis, Centro de Investigaciones Biológicas del Noroeste, México 148 pp.

Santovito, G., Piccinni, E., Cassini, A., Irato, P., Albergoni, V., 2005. Antioxidant responses of the Mediterranean mussel, Mytilus galloprovincialis, to environmental variability of dissolved oxygen. Comp. Biochem. Physiol. C 140, 321-329.

Seguineau, C., Soudant, P., Moal, J., Delaporte, M., Miner, P., Quéré, C., Samain, J.F., 2005. Techniques for delivery of arachidonic acid to Pacific oyster, Crassostrea gigas, spat: a preliminary investigation. Lipids 40, 1-9.

Soudant, P., Van Ryckeghem, K., Marty, Y., Moal, J., Samain, J.F., Sorgeloos, P., 1999. Comparison of the lipid class and fatty acid composition between a reproductive cycle in nature and a standard hatchery conditioning of the Pacific oyster Crassostrea gigas. Comp. Biochem. Physiol. B123, 209-222.

Spiteller, G., 2006. Peroxyl radicals: Inductors of neurodegenerative and other inflammatory diseases. Their origin and how they transform cholesterol, phospholipids, plasmalogens, polyunsaturated fatty acids, sugars, and proteins into deleterious products. Free Radic. Biol. Med. 41, 362-387.

Stables, M.J., Gilroy, D.W., 2011. Old and new generation lipid mediators in acute inflammation and resolution. Prog. Lipid. Res. 50, 35-51.

Stanley, D.W., Miller, J.S., 2006. Eicosanoid actions in insect cellular immune functions. Entomol. Exp. Appl. 119, 1-13.

Toda, A., Y.T., Shimizu, T., 2002. Leukotriene B4 receptors. Prostaglandins Other Lipid Mediat. 68-69, 575-585.

Tocher, D.R., Bell, J.G., Farndale, B.M., Sargent, J.R., 1997. Effects of dietary $\alpha$-1inolenic acid rich borage oil combined with marine fish oils on tissue phospholipid fatty acid composition and production of prostaglandins $\mathrm{E}$ and $\mathrm{F}$ of the 1-2 and 3-series in a marine fish deficient in $\Delta 5$ fatty acyl desaturase. Prostaglandins Leukot. Essent. Fatty Acids. 57, 125-134.

Van Anholt, R.D., Spanings, F.A.T., Koven, W.M, Nixon, O., Wendelaar Bonga, S.E., 2004. Arachidonic acid reduces the stress response of gilthead seabream Sparus aurata L. J. Exp. Biol. 207, 3419-3430.

Villalta, M., Estevez, A., Brandsen, M.P., Bell, J.G., 2008. Arachidonic acid, arachidonic/ eicosapentaenoic acid ratio, stearidonic acid and eicosanoids are involved in dietary-induced albinism in Senegal sole (Solea senegalensis). Aquacult. Nutr. 14, 120-128.

\section{Figure captions}

Fig.1. ARA ( $\mu \mathrm{g} / \mathrm{mg}$ wet mass) in phospholipids and lipid reserves of Crassostrea gigas after 30 days of the dietary conditioning with T.iso supplemented with $0,0.25$, and $0.41 \mu \mathrm{g} / \mathrm{mL}$ of ARA $(\mathrm{n}=3$ pools of 5 animals each). Results are reported as mean \pm SE. Means not sharing the same letter within each lipid class are significantly different $(P<0.05)$. 
557 Fig. 2. Prostaglandin E metabolite (PGEM) in Crassostrea gigas before conditioning (T0) and 558 after 15 and 30 days of conditioning with T.iso supplemented with $0,0.25$ and $0.41 \mu \mathrm{g} / \mathrm{mL}$ of 559 ARA. Results are reported as mean \pm SE. Means not sharing the same letter within each time 560 sampling are significantly different $(P<0.05)$ by ANOVA followed by Tukey test. An additional 561 ANOVA was done to analyze the differences as a result of time of conditioning with T.iso + 562 ARA $0 \mu \mathrm{g} / \mathrm{mL}$; significant differences $(P<0.05)$ compared to T0 values are marked by an 563 asterisk $(*)$.

564

565 Fig. 3. Relation between PGEM and ARA levels (lipid reserves + phospholipids) in Crassostrea 566 gigas after 30 days of conditioning with T.iso supplemented with $0,0.25$ and $0.41 \mu \mathrm{g} / \mathrm{mL}$ of

$567 \quad$ ARA. $\mathrm{Y}=1.1+39.2 \mathrm{X}, \mathrm{R}^{2}=0.67, P<0.05$ 
569 Table 1: Fatty acid composition (percent of total fatty acids) in lipid reserves and phospholipids

570 of Crassostrea gigas (whole oyster) after 30 days of the dietary conditioning with T.iso

571 supplemented with $0,0.25$, and $0.41 \mu \mathrm{g} / \mathrm{mL}$ of ARA ( $\mathrm{n}=3$ pools of 5 animals each). Results are

572 reported as Mean \pm SE. Fatty acids in phospholipids and lipid reserves were analyzed

573 separately. Different lower-case letters indicate significant difference between dietary treatments

574 (1-way ANOVA, $P<0.05)$.

\begin{tabular}{|c|c|c|c|c|c|c|}
\hline \multirow[b]{2}{*}{$\begin{array}{l}\text { supplied } \\
\text { ARA } \mu \mathrm{g} / \mathrm{mL}\end{array}$} & \multicolumn{3}{|c|}{ Lipid Reserves } & \multicolumn{3}{|c|}{ Phospholipids } \\
\hline & 0 & 0.25 & 0.41 & 0 & 0.25 & 0.41 \\
\hline $14: 0$ & $5.31 \pm 0.15$ & $4.94 \pm 0.26$ & $4.93 \pm 0.31$ & $1.76 \pm 0.1$ & $1.63 \pm 0.06$ & $1.62 \pm 0.12$ \\
\hline $16: 0$ & $14.0 \pm 0.61$ & $14.4 \pm 0.34$ & $13.5 \pm 0.41$ & $9.81 \pm 0.47$ & $9.40 \pm 00.23$ & $9.04 \pm 0.11$ \\
\hline 18:0 & $2.73 \pm 0.02$ & $3.11 \pm 0.08$ & $2.76 \pm 0.06$ & $4.7 \pm 0.12$ & $5.05 \pm 0.11$ & $4.81 \pm 0.08$ \\
\hline $16: 1 n-7$ & $3.51 \pm 0.27$ & $3.39 \pm 0.24$ & $3.22 \pm 0.17$ & $1.48 \pm 0.09$ & $1.2 \pm 0.04$ & $1.37 \pm 0.06$ \\
\hline $18: 1 n-9$ & $5.52 \pm 0.48$ & $4.67 \pm 0.24$ & $4.72 \pm 0.24$ & $2.17 \pm 6$ & $2.09 \pm 0.04$ & $2 \pm 0.13$ \\
\hline $18: 1 n-7$ & $4.3 \pm 0.03$ & $4.77 \pm 0.08$ & $4.51 \pm 0.13$ & $2.79 \pm 0.22$ & $3.29 \pm 0.09$ & $3.52 \pm 0.08$ \\
\hline $18: 2 n-6$ & $6.54 \pm 0.55$ & $4.9 \pm 0.36$ & $5.43 \pm 0.31$ & $3.08 \pm 0.31$ & $2.54 \pm 0.13$ & $2.66 \pm 0.2$ \\
\hline $18: 3 n-3$ & $3.43 \pm 0.23^{\mathrm{a}}$ & $2.58 \pm 0.19 b$ & $2.81 \pm 0.14^{\mathrm{ab}}$ & $1.35 \pm 0.1 \mathrm{a}$ & $1.17 \pm 0.05^{\mathrm{ab}}$ & $1.12 \pm 0.07^{\mathrm{b}}$ \\
\hline $18: 4 n-3$ & $7.33 \pm 0.23$ & $6.23 \pm 0.3$ & $6.56 \pm 0.18$ & $1.89 \pm 0.03$ & $1.73 \pm 0.08$ & $1.51 \pm 0.1$ \\
\hline $20: 4 n-6$ & $0.96 \pm 0.01^{\mathrm{a}}$ & $4.12 \pm 0.16^{b}$ & $7.46 \pm 0.88^{c}$ & $2.33 \pm 0.06^{\mathrm{a}}$ & $6.89 \pm 0.19^{b}$ & $9.25 \pm 0.31^{\mathrm{c}}$ \\
\hline $20: 5 n-3$ & $13.3 \pm 0.55$ & $14.8 \pm 0.44$ & $13.6 \pm 0.45$ & $10.9 \pm 0.3$ & $10.8 \pm 0.18$ & $10.3 \pm 0.32$ \\
\hline $22: 5 n-6$ & $1.02 \pm 0.1$ & $0.80 \pm 0.06$ & $0.85 \pm 0.04$ & $1.62 \pm 0.01^{\mathrm{a}}$ & $1.47 \pm 0.01^{b}$ & $1.32 \pm 0.07^{\mathrm{c}}$ \\
\hline $22: 5 n-3$ & $0.58 \pm 0.02$ & $0.61 \pm 0.01$ & $0.59 \pm 0.01$ & $1.20 \pm 0.02$ & $1.13 \pm 0.03$ & $1.32 \pm 0.07$ \\
\hline $22: 6 n-3$ & $12.8 \pm 0.35^{\mathrm{a}}$ & $11.4 \pm 0.21^{b}$ & $11.2 \pm .0 .5^{b}$ & $16.4 \pm 0.14^{\mathrm{a}}$ & $15.3 \pm 0.19^{b}$ & $14.3 \pm 0.14^{\mathrm{c}}$ \\
\hline Total PUFA & $53.8 \pm 1.2^{\mathrm{ab}}$ & $52.5 \pm 0.6^{\mathrm{a}}$ & $55.4 \pm 0.8^{b}$ & $49.2 \pm 0.6^{\mathrm{a}}$ & $51.3 \pm 0.4^{\mathrm{b}}$ & $51.2 \pm 0.2^{b}$ \\
\hline Total n-6 & $10.2 \pm 0.65^{\mathrm{a}}$ & $11.4 \pm 0.37^{\mathrm{a}}$ & $15.4 \pm 0.72^{b}$ & $8.8 \pm 0.37^{\mathrm{a}}$ & $13.2 \pm 0.43^{b}$ & $15.6 \pm 0.51^{\mathrm{c}}$ \\
\hline Total n-3 & $39.2 \pm 0.62^{\mathrm{a}}$ & $36.4 \pm 0.52^{b}$ & $37.3 \pm 0.57^{\mathrm{ab}}$ & $33.4 \pm 0.43^{\mathrm{a}}$ & $31.4 \pm 0.18^{b}$ & $29.4 \pm 0.24^{\mathrm{c}}$ \\
\hline$n-3 / n-6$ & $3.86 \pm 0.22^{\mathrm{a}}$ & $3.27 \pm 0.08^{b}$ & $2.37 \pm 0.13^{b}$ & $3.82 \pm 0.2^{\mathrm{a}}$ & $2.39 \pm 0.08^{b}$ & $1.89 \pm 0.07^{\mathrm{c}}$ \\
\hline EPA /ARA & $13.8 \pm 0.41 \mathrm{a}$ & $3.59 \pm 0.04 b$ & $1.87 \pm 0.2 \mathrm{c}$ & $4.68 \pm 0.18 \mathrm{a}$ & $1.56 \pm 0.07 \mathrm{~b}$ & $1.11 \pm 0.06 \mathrm{c}$ \\
\hline $\begin{array}{l}\text { Unsaturated } \\
\text { index (PUI) }\end{array}$ & $227 \pm 3.5^{\mathrm{a}}$ & $227 \pm 1.4^{\mathrm{a}}$ & $236 \pm 2.9^{b}$ & $204 \pm 1.6^{\mathrm{a}}$ & $224 \pm 1.5^{b}$ & $224 \pm 1.1^{b}$ \\
\hline $\begin{array}{l}\text { Peroxidation } \\
\text { index }\end{array}$ & $243 \pm 3.5^{\mathrm{a}}$ & $243 \pm 1.4^{\mathrm{a}}$ & $251 \pm 4^{\mathrm{a}}$ & $239 \pm 2.2^{\mathrm{a}}$ & $244 \pm 1.4^{\mathrm{a}}$ & $240 \pm 0.8^{\mathrm{a}}$ \\
\hline
\end{tabular}


575 Table 2: Lipid peroxidation (measured as malondialdehyde concentration in $\mu \mathrm{mol} / \mathrm{mg}$ wet mass), total antioxidant radical scavenging capacity 576 (measured as DPPH inhibition percentage), catalase and superoxide dismutase activities in Crassostrea gigas before conditioning (T0) and after 15 577 and 30 days of conditioning with T.iso supplemented with $0,0.25$ and $0.41 \mu \mathrm{g} / \mathrm{mL}$ of ARA. Results are reported as Mean \pm SE. Significant effect of 578 treatment evaluated by ANOVA was only observed for DPPH inhibition percentage; means not sharing the same letter within each time sampling 579 are significantly different by Tukey test. An additional ANOVA was done to analyze the differences as a result of time of conditioning with T.iso + 580 ARA $0 \mu \mathrm{g} / \mathrm{mL}$; significant differences $(P<0.05)$ compared to T0 values are marked by *.

581

\begin{tabular}{|c|c|c|c|c|c|c|c|}
\hline \multirow[b]{2}{*}{ supplied ARA $\mu \mathrm{g} / \mathrm{mL}$} & \multirow[t]{2}{*}{ T0 } & \multicolumn{3}{|c|}{$\begin{array}{c}\text { T15 } \\
\text { (after } 2 \text { weeks of feeding ARA) }\end{array}$} & \multicolumn{3}{|c|}{$\begin{array}{c}\text { T30 } \\
\text { (after } 4 \text { weeks of feeding ARA) }\end{array}$} \\
\hline & & 0 & 0.25 & 0.41 & 0 & 0.25 & 0.41 \\
\hline $\begin{array}{l}\text { Malondialdehyde (MDA) } \\
(\mu \mathrm{mol} / \mathrm{mg} \text { wet mass) }\end{array}$ & $0.057 \pm 0.004$ & $0.044 \pm 0.003$ & $0.044 \pm 0.005$ & $0.052 \pm 0.005$ & $0.056 \pm 0.008$ & $0.046 \pm 0.002$ & $0.059 \pm 0.004$ \\
\hline DPPH inhibition percentage & $24.48 \pm 6.89$ & $20.73 \pm 0.76^{\mathrm{a}}$ & $14.9 \pm 2.75^{\mathrm{a}}$ & $29.84 \pm 0.47^{b}$ & $16.94 \pm 0.68^{a}$ & $12.11 \pm 0.64^{\mathrm{a}}$ & $17.27 \pm 2.52^{\mathrm{a}}$ \\
\hline $\begin{array}{l}\text { Catalase } \\
\text { (U/ mg wet mass) }\end{array}$ & $2.5 \pm 0.16$ & $2.5 \pm 0.39$ & $2.27 \pm 0.12$ & $2.31 \pm 0.04$ & $2.55 \pm 0.17$ & $2.27 \pm 0.27$ & $2.4 \pm 0.13$ \\
\hline $\begin{array}{l}\text { Superoxide dismutase (SOD) } \\
\text { (U/mg wet mass) }\end{array}$ & $1.76 \pm 0.14$ & $2.89 \pm 0.16^{*}$ & $1.86 \pm 0.36$ & $2.91 \pm 0.92$ & $3.16 \pm 0.25^{*}$ & $2.37 \pm 0.38$ & $2.78 \pm 0.13$ \\
\hline
\end{tabular}


588 Figure 1

589

590

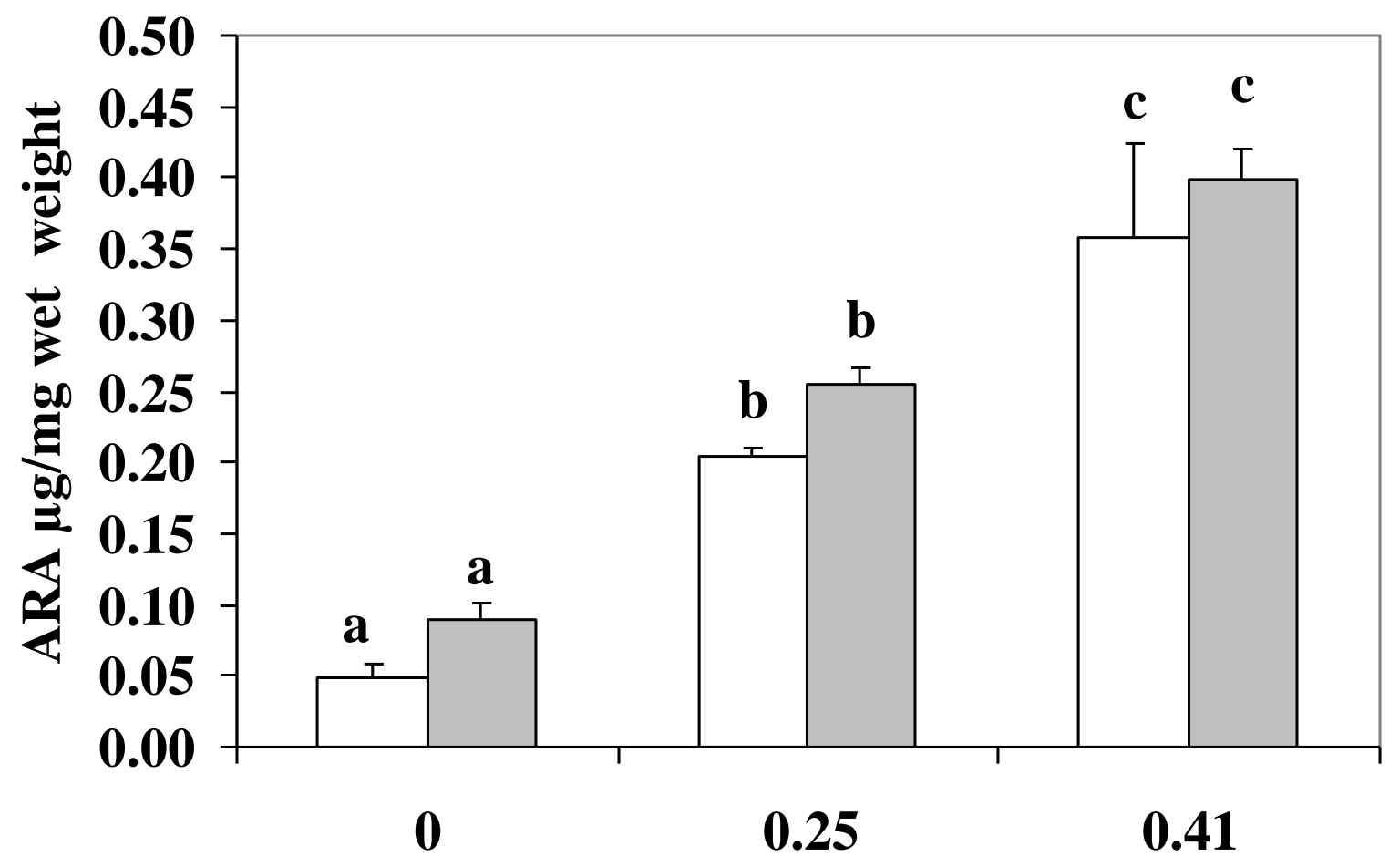

ARA supplementation in $\mu \mathrm{g} / \mathrm{mL}$ 
592

593

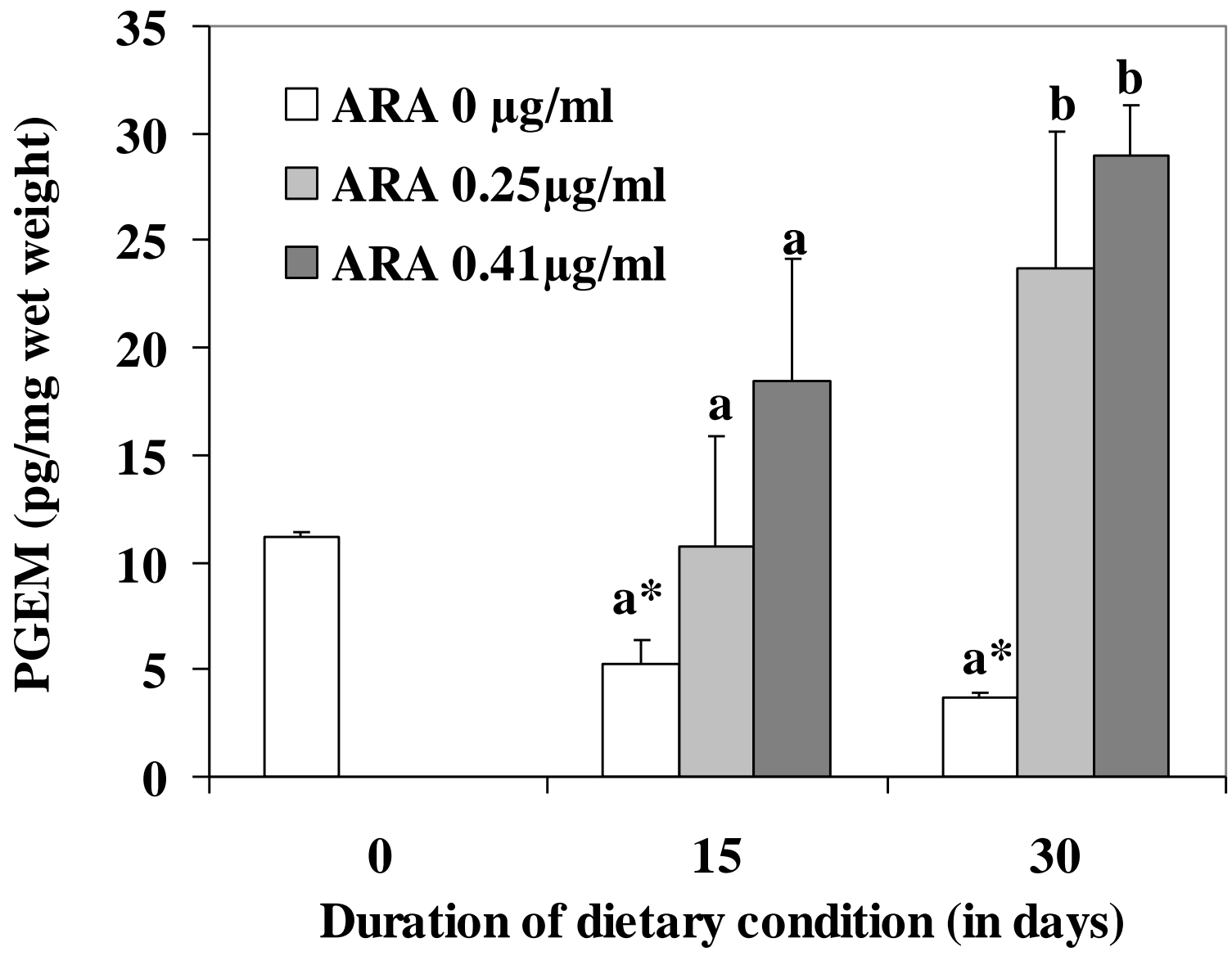

594

595

596

597

Figure 2 


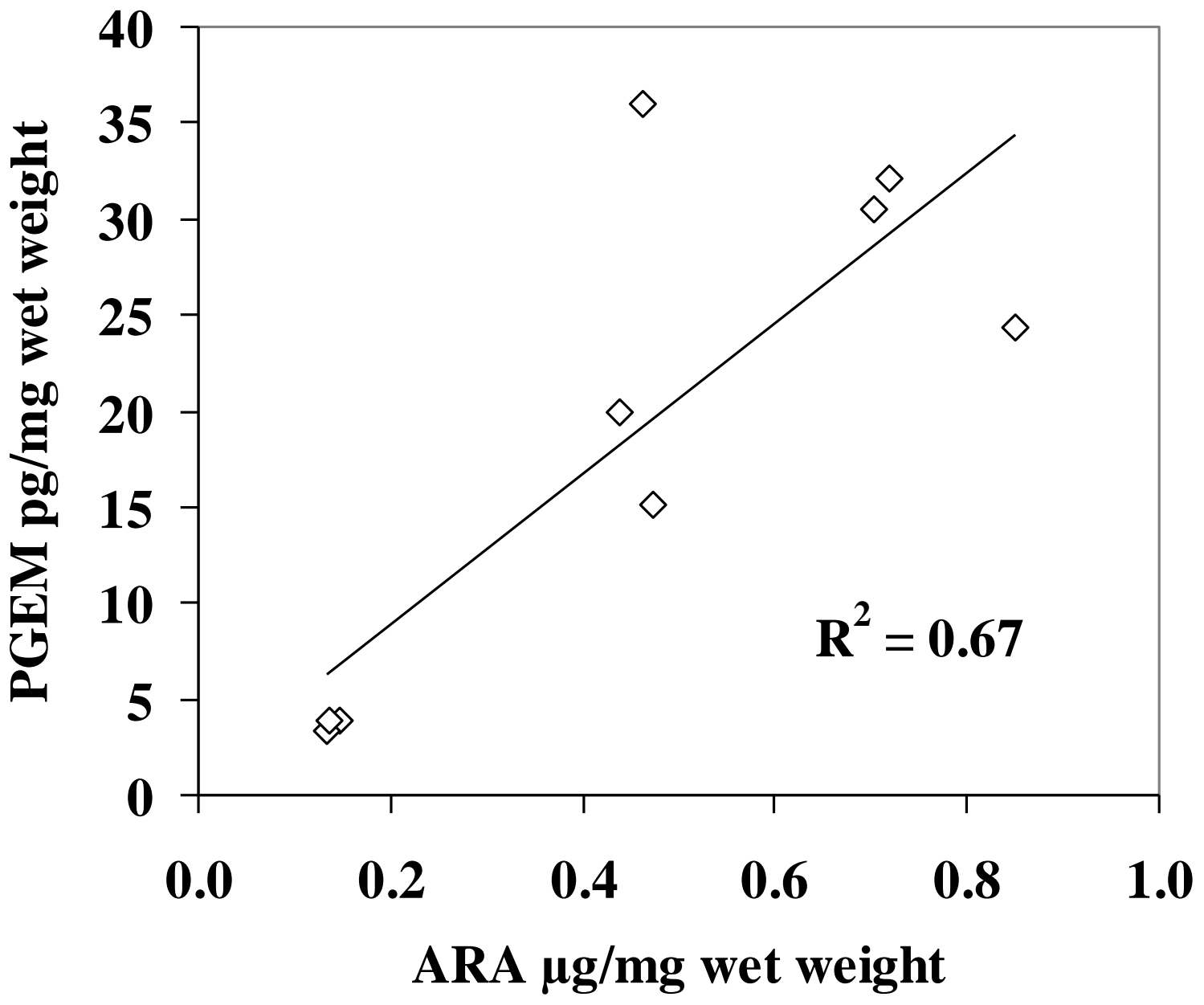

600

601

602 Figure 3

603

604

605

606 